\title{
Trajectories of endurance activity following pulmonary rehabilitation in COPD patients
}

\author{
J.E. Soicher*,\#, N.E. Mayo ${ }^{\#, \uparrow,+}$, L. Gauvin ${ }^{\S}$, J.A. Hanley ${ }^{\uparrow,+}$, S. Bernard ${ }^{f}$, \\ F. Maltais ${ }^{f}$ and J. Bourbeau*,+
}

ABSTRACT: Maintenance of physical activity following pulmonary rehabilitation remains a challenge for patients with chronic obstructive pulmonary disease (COPD). The objectives of this study were to identify patterns of endurance activity after completion of pulmonary rehabilitation and to characterise people who succeed and those who have difficulty maintaining endurance activity.

In a longitudinal study embedded within a randomised clinical trial, 206 individuals with COPD underwent a 3-month pulmonary rehabilitation programme. Weekly duration of endurance activity was assessed at 4, 6, 8 and 12 months after the start of rehabilitation. Trajectory modelling was used to determine the most common patterns of activity during the post-rehabilitation phase from 412 months.

Three distinct patterns were identified, two of which indicated difficulty in maintaining endurance activity: 61 individuals reported a high activity level at 4 months (2.7 h. week $\left.{ }^{-1}\right)$ and stayed high; 114 individuals started at a low activity level (mean $1.0 \mathrm{~h} \cdot$ week $^{-1}$ ) and stayed low; and 31 individuals started high (3.0 h.week ${ }^{-1}$ ) and declined. The low activity group was characterised by more severe disease and greater respiratory impairment. The high and declined group had less severe disease and respiratory impairment, but reported greater barriers to exercise.

Pulmonary rehabilitation should include interventions aimed at minimising barriers, in order to induce long-term behaviour change.

KEYWORDS: Behavioural medicine, chronic obstructive pulmonary disease, exercise, rehabilitation

$\mathbf{T}$ he short-term effectiveness of pulmonary rehabilitation in improving exercise capacity and health status is well established [1]; however, sustained long-term physical activity remains a challenge for patients with chronic obstructive pulmonary disease (COPD) [2]. Although several studies have reported attendance during the initial programme [3-5] or organised maintenance sessions [3, 4], few have documented physical activity in detail during the post-programme or maintenance phase when patients must exercise on their own. In a randomised controlled trial [6] that evaluated a telephone follow-up intervention after rehabilitation, $\sim 70 \%$ (intervention group) and 90\% (control group) of patients reported doing regular home exercise at 3 months after rehabilitation start, and these values dropped to $\sim 50 \%$ by 12 months. While physical activity following rehabilitation appears insufficient overall, there is likely to be heterogeneity among COPD patients, with some maintaining activity better than others.

Patients with COPD who maintain activity have less dyspnoea during daily activity, better health-related quality of life [7], and enhanced long-term functional
[8], physiological and psychological outcomes [9]. In order to develop and implement cost-effective physical activity maintenance interventions in the clinical setting, however, more information is needed on the sociodemographic and disease-related characteristics of individuals with differing patterns of physical activity following rehabilitation. The contribution of behavioural characteristics, such as past exercise habits $[10,11]$, self-efficacy for exercise $[10,12]$, and perceived barriers to exercise $[11,13]$ should also be considered, as these variables have been significantly associated with physical activity maintenance among elderly [10] and chronic disease populations [11-13].

Information on patient characteristics, associated with physical activity maintenance, can guide clinicians in identifying early in the rehabilitation process people who may have difficulty in maintaining physical activity, and the specific areas on which to focus interventions. In this study, we operationalised physical activity as the weekly duration of endurance activities, as guidelines for adults with chronic disease emphasise that greater amounts of endurance activity result in additional
AFFILIATIONS

${ }^{*}$ Respiratory Epidemiology and Clinical Research Unit, Montreal Chest Institute,

'Division of Clinical Epidemiology, Royal Victoria Hospital, McGill University Health Centre,

${ }^{\#}$ School of Physical and Occupational Therapy,

${ }^{+}$Dept of Epidemiology, Biostatistics and Occupational Health, Faculty of Medicine, McGill University,

${ }^{\S}$ Département de Médecine Sociale and Préventive, Université de Montréal, Centre de Recherche du Centre Hospitalier de l'Université de Montréal, Montréal, and f Institut Universitaire de Cardiologie et de Pneumologie et de Québec, Université Laval, Québec, Québec, Canada.

CORRESPONDENCE

J. Bourbeau

Respiratory Epidemiology and

Clinical Research Unit

Montreal Chest Institute

3650 St. Urbain

Office K1.32

Montréal

H2X 2P4

Canada

E-mail: jean.bourbeau@mcgill.ca

Received:

Feb 102011

Accepted after revision:

May 232011

First published online:

July 072011 
health benefits and higher levels of cardiovascular fitness [14]. Objectives of this study were as follows: 1) to identify patterns of endurance activity following pulmonary rehabilitation; and 2) to characterise people who succeed and those who have difficulty maintaining endurance activity.

\section{METHODS}

\section{Study design}

We carried out a two-phase longitudinal observational study. The first phase consisted of a 3-month pulmonary rehabilitation programme (0-3 months), and the second phase covered the post-rehabilitation follow-up phase (4 months-1 yr). Both phases of the longitudinal study were embedded within a randomised clinical trial comparing the effectiveness of outpatient hospitalbased versus self-monitored home-based exercise training. All subjects participated in 4 weeks of hospital-based self-management education, after which they were randomised to 8 weeks of either hospital- or home-based exercise training scheduled three times per week (3-month pulmonary rehabilitation programme). At the end of the programme, participants in both groups were instructed to continue exercising on their own at least three times per week, for 30-45 min per session, and were encouraged to join a community exercise facility or to purchase exercise equipment for home use. Following completion of the programme, subjects were contacted by telephone every 2 months by a nurse case manager to reinforce the importance of continued exercise. Patients were also encouraged to phone the case manager and exercise specialist with questions that arose following the rehabilitation programme. The trial intervention and results have been previously reported [15]. In this article, we report specifically on the post-rehabilitation follow-up phase of the longitudinal study, as little is known about the maintenance aspect of pulmonary rehabilitation. Results were based on the following measures: baseline subject characteristics, exacerbations recorded during the entire study period, and endurance activity assessed at 4, 6, 8 and 12 months after the start of rehabilitation (maintenance phase).

\section{Subjects}

Individuals with a diagnosis of COPD were recruited from 10 participating centres across Canada and were included if they were community-dwelling, able to ambulate $>110 \mathrm{~m}$ in $6 \mathrm{~min}$, had fixed airway obstruction and no serious comorbidity. Ethical approval was obtained from participating centres and subjects gave written informed consent. Of 252 individuals participating in the randomised trial, 206 subjects underwent assessment of endurance activity from 4 months to $1 \mathrm{yr}$. Therefore, the sample on which we are reporting in this manuscript consisted of 206 subjects.

\section{Assessment of baseline subject characteristics}

Sociodemographic information, body mass index (BMI), oxygen use, smoking and comorbid conditions were recorded. Forced expiratory volume in $1 \mathrm{~s}$ (FEV1) was measured by spirometry using reference values from KNUDSON et al. [16]. The Modified Medical Research Council (MMRC) dyspnoea scale [17], 6-min walk test [18] (best of two trials), St George's Respiratory Questionnaire [19] and Geriatric Depression Scale [20] were also administered. Exercise habits during the 3 months prior to starting rehabilitation were evaluated as: no exercise, sporadic exercise (1-3 times per month, any duration), exercise at least once per week for $<20$ min per session, or exercise at least once per week for $\geqslant 20 \mathrm{~min}$ per session. Self-efficacy was measured using five items that assessed a person's confidence in performing endurance activity of progressively longer session duration (range 5-40 $\mathrm{min}$ ). Each item was scored on a scale from $0 \%$ (not at all confident) to $100 \%$ (highly confident), and an average score was calculated [21]. Perceived barriers to exercise were evaluated using the barriers section of the Exercise Benefits/Barriers Scale [22]. This instrument lists 13 common barriers to exercise. A barrier was considered to be endorsed if subjects responded "agree" or "strongly agree."

\section{Disease exacerbations}

Disease exacerbations were recorded by monthly telephone interviews at the end of months 4-11, and at the 1-yr visit, based on daily completion of a diary card for symptoms. An exacerbation was defined as a worsening of at least one respiratory symptom (dyspnoea, sputum production and sputum colour) for a period of $\geqslant 24 \mathrm{~h}$. Exacerbations were classified as mild, moderate or severe, according to the definitions of WEDZICHA and SEEMUNGAL [23].

\section{Outcome assessment}

Endurance activities were assessed using a 1-week exercise log administered by semi-structured telephone (4, 6 and 8 months) or face-to-face $(1 \mathrm{yr})$ interview. The log was based on the 7-Day Physical Activity Recall questionnaire, which has demonstrated reliability and validity in a variety of populations [24] and is feasible for telephone administration [25]. To minimise response burden and difficulty with recall, data were collected for the week preceding the interview, as a sample of the subject's typical endurance activity over the previous months. Subjects were also asked if the past week had been typical with respect to activity; if the week was not typical (more or less activity than usual), the reason was documented. Data were collected for the following activities: stationary or regular bicycling, treadmill or over ground walking, stairmaster or stair climbing, or any other type of endurance activity. Subjects reported on which days (over the past 7 days) each activity was carried out and the activity duration. Values were then summed to yield total weekly duration of endurance activity.

\section{Statistical analysis}

Due to skewed distribution, the weekly duration of endurance activity was categorised as 0, 1-60, 61-120, 121-180 and $>180 \mathrm{~min}$ per week, corresponding to 1 -h increments in activity and labelled as categories 0 to 4 . Category of endurance activity (0-4) was treated as a continuous variable and its trajectory was modelled over four time-points (4, 6, 8 and 12 months) using latent class growth analysis [26]. Trajectory modelling identifies subgroups (classes) of individuals with similar patterns over time and estimates a mean growth curve for each class, with intercept and slope variances specified as zero within each class. Model selection was based on indices of model fit (Bayesian information criterion, Lo-Mendell-Rubin likelihood ratio test).

Baseline subject characteristics and the initial rehabilitation setting (home or hospital) were compared among trajectory classes, using ANOVA and Chi-squared tests for continuous and categorical variables, respectively. For continuous variables, specific comparisons were carried out through ANOVA to 
determine which of the subgroups were significantly different. For categorical variables, this type of comparison would require multiple post hoc tests, thereby increasing the likelihood of a type I statistical error (probability of finding a difference when none exists). Statistical comparisons can be carried out conservatively to yield overall differences among the three classes. Stepwise multivariate discriminant analysis was also carried out to verify the findings from univariate comparisons. The decision to compare subject characteristics measured at baseline, rather than post-rehabilitation or pre-post change values, was based on two main considerations: 1) sociodemographic characteristics, FEV1 and dyspnoea classification did not change appreciably over time; and 2) baseline values are useful indicators as they can be used to identify, early in the rehabilitation process, patients at risk of poor maintenance of endurance activity, and implement appropriate monitoring and follow-up strategies.

Mplus software Version 4.2 (Muthen \& Muthen, Los Angeles, CA, USA) was used for trajectory modelling [27], with simulation studies suggesting that simple trajectory models can be estimated with as few as 20 subjects. Therefore, the sample of over 200 subjects was sufficient. Other analyses were carried out using SAS Version 9.1 (SAS Institute Inc., Cary, NC, USA).

\section{RESULTS}

Of the 252 subjects participating in the randomised trial, 37 (15\%) were not included in the longitudinal study due to missing information. This group was similar to the remaining subjects $(n=215)$ on baseline sociodemographic characteristics, lung function and health status. Of the 215 remaining subjects, nine dropped out during the follow-up phase and did not contribute data on physical activity. In the 46 individuals (37 plus nine) not included in the longitudinal study, a higher proportion reported severe dyspnoea, compared with the 206 subjects comprising the study sample ( $41 \%$ versus $24 \%$ ), but they were similar in all other baseline characteristics.

Baseline characteristics are presented in table 1. Participants were older adults, slightly more than half were male, and the majority had a BMI that was either normal or overweight. Mean FEV1 indicated severe airflow obstruction [28], almost a quarter reported severe dyspnoea with activity, and more than half reported having at least one comorbid condition.

Table 2 presents a descriptive summary of the median duration of endurance activity (interquartile range) and the number (percentage) of individuals in each category, at each evaluation timepoint. Overall, the weekly time of endurance activity declined following completion of a 3-month rehabilitation programme.

\section{Trajectory models}

Two-, three-, and four-class trajectory models are summarised in table 3, with respect to subject classification and model fit. The three-class model was selected based on the best combination of fit indices (lower Bayesian information criterion, significant LoMendell-Rubin test). The three trajectory classes were labelled "high" (average $2.7 \mathrm{~h}$ per week endurance activity at 4 months, $3.2 \mathrm{~h}$ per week at 12 months), "low" (1.0 h per week at 4 months, $0.7 \mathrm{~h}$ per week at 12 months), and "high/decline" (3.0 h per week at 4 months, $0.8 \mathrm{~h}$ per week at 12 months). These trajectory classes describe the level and pattern of activity, and comprised

\section{TABLE 1 Baseline characteristics of subjects}

\begin{tabular}{|c|c|}
\hline Age yrs & $66 \pm 8$ \\
\hline \multicolumn{2}{|l|}{ Sex } \\
\hline Male & $116(56)$ \\
\hline Female & $90(44)$ \\
\hline \multicolumn{2}{|l|}{$\mathrm{BMI}^{\#}$} \\
\hline Underweight & $9(4)$ \\
\hline Normal & $66(32)$ \\
\hline Overweight & $72(35)$ \\
\hline Obese & $59(29)$ \\
\hline Supplemental oxygen use for exercise & $13(6)$ \\
\hline \multicolumn{2}{|l|}{ Smoking status } \\
\hline Nonsmoker" & $1(0.5)$ \\
\hline Ex-smoker & $169(82.0)$ \\
\hline Current smoker & $36(17.5)$ \\
\hline \multicolumn{2}{|l|}{ Comorbid conditions } \\
\hline 0 & $90(44)$ \\
\hline 1 & $87(42)$ \\
\hline $2-3$ & $29(14)$ \\
\hline \multicolumn{2}{|l|}{ Marital status } \\
\hline Single, separated, divorced or widowed & $94(46)$ \\
\hline Married or common law & $112(54)$ \\
\hline FEV1 L & $1.1 \pm 0.4$ \\
\hline FEV $1 \%$ pred & $44.4 \pm 13$ \\
\hline \multicolumn{2}{|l|}{ Disease severity (GOLD classification) ${ }^{+}$} \\
\hline II - moderate & $71(34)$ \\
\hline III - severe & $107(52)$ \\
\hline IV - very severe & $28(14)$ \\
\hline \multicolumn{2}{|l|}{ Dyspnoea $^{\S}$} \\
\hline Mild-moderate & $157(76)$ \\
\hline Severe & $49(24)$ \\
\hline 6-min walk distance ${ }^{f} \mathbf{m}$ & $369 \pm 86$ \\
\hline Health status ${ }^{\# \#} \%$ & $46 \pm 15$ \\
\hline \multicolumn{2}{|l|}{ Depression $"$} \\
\hline None & $153(75)$ \\
\hline Possible/probable & $51(25)$ \\
\hline
\end{tabular}

Data are presented as mean \pm SD or $n(\%)$. BMI: body mass index; FEV 1 : forced expiratory volume in $1 \mathrm{~s}$; $\%$ pred: \% predicted; GOLD: Global Initiative for Chronic Obstructive Lung Disease. \#: BMl categorised as: underweight, $<18.5 \mathrm{~kg} \cdot \mathrm{m}^{-2}$; normal, $18.5-24.9 \mathrm{~kg} \cdot \mathrm{m}^{-2}$; overweight, 25-29.9 $\mathrm{kg} \cdot \mathrm{m}^{-2}$; obese, $\geqslant 30 \mathrm{~kg} \cdot \mathrm{m}^{-2}$. $\because$ : one subject reported being a nonsmoker, but had spirometry values characteristic of fixed airway obstruction and was therefore retained in the study sample. ${ }^{+}$: disease severity classified according to the GOLD guidelines [28]: stage I, mild, FEV1 $\geqslant 80 \%$ of predicted normal value; stage II, moderate, FEV1 50-79\%; stage III, severe, FEV1 30-49\%; stage IV, very severe, FEV $1<30 \%$. s. dyspnoea measured using Modified Medical Research Council dyspnoea scale: mild-moderate dyspnoea, grade 1-3; severe dyspnoea, grade 4-5. ${ }^{f}: \mathrm{n}=205 ;{ }^{\# \#}$ : health status measured using St George's Respiratory Questionnaire total score, where higher score represents worse health status. " $:$ depression measured using Geriatric Depression Scale: 0-5, no depression; 6-10, possible depression; 11-15, probable depression $(n=204)$.

30,55 and $15 \%$ of the sample, respectively. The three-class model is illustrated in figure 1.

\section{Comparison of subject characteristics across trajectory classes}

Selected subject characteristics are summarised, by trajectory class, in table 4 . No significant differences among classes were 
TABLE 2 Reported time spent in endurance activities during the previous week, at four time-points during year

\begin{tabular}{|c|c|c|c|c|c|}
\hline & \multirow[t]{2}{*}{ Time spent min per week } & \multicolumn{4}{|c|}{ Month } \\
\hline & & 4 & 6 & 8 & 12 \\
\hline Median min per week & & $80(20-150)$ & $75(0-150)$ & $70(0-125)$ & $50(0-125)$ \\
\hline \multicolumn{6}{|l|}{ Category ${ }^{\#}$} \\
\hline 0 & 0 & $46(23)$ & $49(26)$ & $65(34)$ & $63(34)$ \\
\hline 3 & $121-180$ & $33(17)$ & $41(22)$ & $32(17)$ & $24(13)$ \\
\hline 4 & $>180$ & $37(19)$ & $30(16)$ & $22(11)$ & $25(13)$ \\
\hline
\end{tabular}

Data are presented as median (interquartile range) or $n(\%)$, unless otherwise stated. ${ }^{\#}:$ sum of percentage values may not equal 100 due to rounding

observed for age, sex or health status. Subjects in the low group had more severe disease and dyspnoea, shorter 6-min walk distance at baseline, were less likely to have exercised in the past, were less likely to have high baseline self-efficacy, and were more likely to have had an exacerbation during follow-up. Higher proportions of smokers and individuals with comorbidity were observed in the low group; however, differences were not statistically significant.

The high/decline group had a lower proportion of subjects with severe or very severe disease, and with severe dyspnoea. $65 \%$ of subjects reported three or more barriers to exercise at baseline, compared with 55 and 31\% in low and high groups, respectively. Barriers frequently endorsed within the high/decline group were: "exercise is tiring" by $77 \%$ (versus $68 \%$ low group $/ 57 \%$ high group), "costs too much to exercise" (35\% versus 18\%/13\%), "family-related barrier" (19\% versus 11\%/10\%), and "places to exercise too far away" (26\% versus $19 \% / 16 \%)$. The high/decline group also had the highest proportion of individuals working full-time, part-time or as a homemaker, although the difference across groups was not statistically significant.

Stepwise multivariate discriminant analysis yielded three variables that discriminated significantly between trajectory classes
( $p<0.05)$ : past exercise habits, 6 -min walk distance and barriers to exercise. The interpretation of this analysis is that, among all variables entered in the model, these three variables discriminated most strongly between trajectory groups. The multivariate results therefore confirm those obtained in univariate comparisons.

Of the total responses for weekly physical activity (all timepoints), $13 \%$ of responses were qualified as occurring during an atypical activity week. Several significant differences were detected between groups and are reported here to provide complementary information to the 4-12-month activity trajectories. At 4 months, $18.4 \%$ of individuals in the low group reported a medical reason for doing less activity than usual (versus $6.7 \%$ in high group and $3.3 \%$ in high/decline group; $\mathrm{p}<0.05$ ), and the majority of reasons were COPD related. At 8 months, $12.9 \%$ in the high/decline group cited a major life event, such as moving house or a family illness/death (versus $3.9 \%$ in low and $1.7 \%$ in high; $\mathrm{p}<0.05$ ). At 12 months, $20.7 \%$ in the high/decline group reported a medical reason (versus $2.9 \%$ in low and $0 \%$ in high; $\mathrm{p}<0.0001$ ); however, the majority were unrelated to COPD.

\section{DISCUSSION}

For individuals with COPD, time spent in endurance activities showed an overall decline following completion of a 3-month

\section{TABLE 3 Summary of trajectory models}

\begin{tabular}{|c|c|c|c|c|}
\hline Model & Description of trajectories & Subjects $^{\#}$ n (\%) & Bayesian information criterion & Lo-Mendell-Rubin test ${ }^{+} p$-value \\
\hline \multirow[t]{2}{*}{ Two-class } & High & 64 (31) & 2614 & 0.03 \\
\hline & Low & $142(69)$ & & \\
\hline \multirow{2}{*}{ Three-class } & Low & $114(55)$ & & \\
\hline & High/decline & $31(15)$ & & \\
\hline \multirow[t]{3}{*}{ Four-class } & High & $34(17)$ & 2573 & 0.06 \\
\hline & High/decline & $41(20)$ & & \\
\hline & Low/improve & 49 (24) & & \\
\hline
\end{tabular}

\footnotetext{
\#: a subject's trajectory class was the one to which he/she had the highest probability of belonging; ${ }^{\prime}$ : a lower value indicates better model fit; ${ }^{+}:$a likelihood ratio test of model fit. The $\mathrm{p}$-value represents the probability that the data have been generated by a model with one less class. A low $p$-value $(<0.05)$ indicates that the model with one less class is rejected in favour of the estimated model.
} 


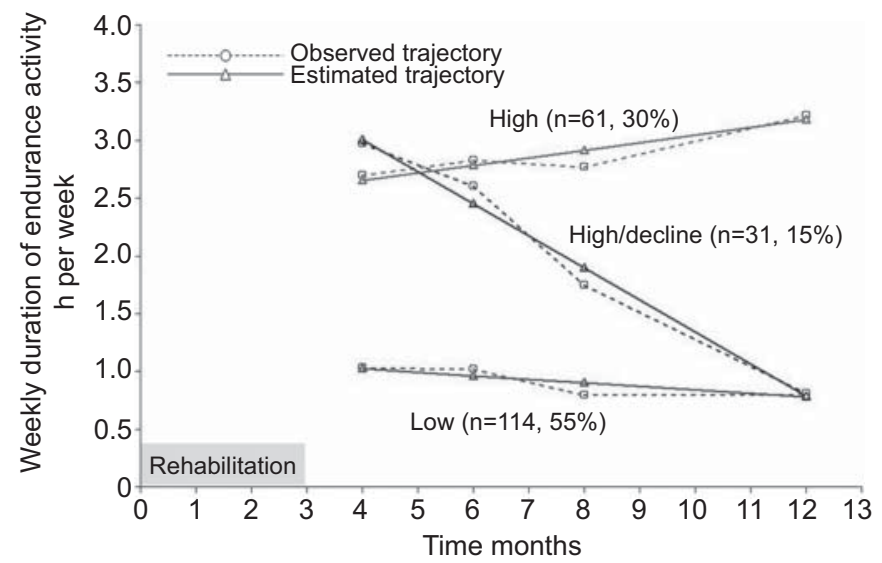

FIGURE 1. Three-class model showing the mean observed and estimated trajectories. The weekly duration of endurance activity plotted against time for high, high/decline and low trajectory groups. The grey box indicates the 3-month pulmonary rehabilitation programme.

pulmonary rehabilitation programme. There was heterogeneity within the study sample, however, as three distinct trajectories (classes) of activity were identified: individuals who started at a high level and stayed high, individuals who started low and stayed low, and individuals who started high and declined. The low activity group was characterised by more severe disease and greater impairments in respiratory and functional status. The high/decline group had less severe disease and respiratory impairment, but reported greater barriers to exercise.

Physical activity recommendations have been published for older adults ( $\geqslant 65 \mathrm{yrs}$ ) and adults aged 50-65 yrs with chronic health conditions [14]. For aerobic activity, the recommendation is to perform moderate-intensity endurance activities for $\geqslant 30 \mathrm{~min}$ on 5 days each week, or vigorous-intensity activity for $\geqslant 20 \mathrm{~min}$ on 3 days each week. If $120 \mathrm{~min}$ per week (30 min on 4 days) is considered a minimal acceptable amount of activity, only $36 \%$ of subjects in our study met this standard at 4 months, and the proportion declined to $26 \%$ at 12 months. This finding of overall insufficient activity is consistent with a previous cross-sectional study [29], in which COPD patients spent significantly less time per day than healthy individuals in walking and standing, and more time in sitting and lying positions. A different picture emerges, however, if each trajectory class is considered separately. Individuals in the high trajectory reported $\sim 3 \mathrm{~h}$ of weekly endurance activity throughout the post-rehabilitation phase up to $1 \mathrm{yr}$, thereby meeting recommendations for adults with chronic conditions. This was not the case for individuals in the low trajectory who reported $\leqslant 1 \mathrm{~h}$ of weekly activity. Individuals in the high/decline group met activity recommendations shortly after completion of rehabilitation at 4 months, and then declined to a level similar to the low group at 12 months.

We considered subjects classified in the low and high/decline trajectories to be those having difficulty maintaining endurance activity, accounting for $70 \%$ of the sample. The low group was characterised by more severe airway obstruction, dyspnoea, shorter 6-min walk distance, poor past exercise habits, worse selfefficacy for exercise, and being more prone to disease exacerbations. These individuals were also more likely to cite a medical

\begin{tabular}{|c|c|c|c|}
\hline & \multicolumn{3}{|c|}{ Trajectory class } \\
\hline & Low & High & High/decline \\
\hline Subjects $\mathrm{n}$ & 114 & 61 & 31 \\
\hline \multicolumn{4}{|l|}{ Baseline characteristic } \\
\hline Age yrs & $67 \pm 8$ & $65 \pm 9$ & $63 \pm 7$ \\
\hline Female sex & 44 & 43 & 45 \\
\hline Work $^{\#}$ & 18 & 16 & 26 \\
\hline Current smoker & 21 & 11 & 16 \\
\hline Comorbid conditions $\geqslant 1$ & 65 & 48 & 42 \\
\hline \multicolumn{4}{|l|}{ Disease severity (GOLD) } \\
\hline II - moderate & $27^{*}$ & $39^{*}$ & $52^{*}$ \\
\hline III - severe & 54 & 53 & 45 \\
\hline IV - very severe & 19 & 8 & 3 \\
\hline Severe dyspnoea ${ }^{+}$ & $31 *$ & $20^{\star}$ & $6^{*}$ \\
\hline 6 -min walk test ${ }^{5}$ & $347 \pm 91^{* * *}$ & $399 \pm 71^{\star \star *}$ & $390 \pm 78^{* \star *}$ \\
\hline Health status ${ }^{f}$ & $47 \pm 14$ & $44 \pm 14$ & $44 \pm 16$ \\
\hline Past exercise habits, any & $45^{\star \star}$ & $77^{\star \star}$ & $61^{\star \star}$ \\
\hline High self-efficacy & $44^{\star}$ & $66^{\star}$ & $48^{*}$ \\
\hline Barriers to exercise, $\geqslant 3$ & $55^{\star *}$ & $31^{\star *}$ & $65^{\star \star}$ \\
\hline Home rehabilitation setting & 50 & 48 & 58 \\
\hline \multicolumn{4}{|l|}{ Exacerbation during follow-up ${ }^{\# \#}$} \\
\hline Exacerbation of any severity & $66^{*}$ & $43^{*}$ & $52^{*}$ \\
\hline Moderate or severe exacerbation & $51^{*}$ & $28^{*}$ & $35^{\star}$ \\
\hline
\end{tabular}

Data are presented as mean \pm SD or \%, unless otherwise stated. GOLD: Global Initiative for Chronic Obstructive Lung Disease. ${ }^{\#}$ : full-time, part-time, homemaker. ': disease severity classified according to the GOLD guidelines [28]: stage $\mathrm{I}$, mild, forced expiratory volume in $1 \mathrm{~s}(\mathrm{FEV} 1) \geqslant 80 \%$ of predicted normal value; stage II, moderate, FEV1 50-79\%; stage III, severe, FEV1 30-49\%; stage IV, very severe, FEV $1<30 \% .^{+}$: dyspnoea measured using Modified Medical Research Council dyspnoea scale: mild-moderate dyspnoea, grade 1-3; severe dyspnoea, grade 4-5. ${ }^{\text {s. }: ~} \mathrm{n}=205 .{ }^{f}$ : health status measured using St George's Respiratory Questionnaire total score, where higher score represents worse health status. ${ }^{\# *}:$ 4-12 months. ${ }^{*}: p<0.05$; ${ }^{* *}: p<0.01$; ${ }^{* * *}: p<0.001$. Between-class difference was statistically significant, using one-way ANOVA for continuous variables and Chi-squared test for categorical variables.

reason related to COPD for doing less activity than usual at 4 months, and this lower level of activity persisted throughout the study period. Therefore, in this subgroup, difficulty maintaining endurance activity was influenced largely by COPDrelated symptoms and functional limitations. In contrast, individuals in the high/decline group had less severe airway obstruction and dyspnoea, but were more likely to report barriers to exercise related to cost, family and exercise facilities, and included a higher percentage who were working. Individuals in this group were also more likely to cite a life event at 8 months and a medical condition unrelated to COPD at 12 months as reasons for doing less activity than usual. Overall, in the high/ decline group, practical barriers, life events and general health issues appeared to hinder endurance activity to a greater extent than COPD-related factors.

Baseline disease severity (based on FEV1) and 6-min walk distance differed among trajectory classes. These findings are consistent with previous cross-sectional studies in which physical 
activity, measured by an activity monitor, was strongly associated with 6-min walk distance $(\mathrm{r}=0.60$ [30] and 0.76 [29]), and was moderately associated with FEV1 ( $\mathrm{r}=0.37$ [30] and 0.28 [29]). KAPLAN et al. [12] previously showed that changes in self-efficacy for walking mediated compliance with a 3-month walking programme in individuals with COPD. Our findings further support the importance of self-efficacy, which differed significantly among classes (Chi-squared $\mathrm{p}<0.05)$. The majority of individuals in the low trajectory reported at baseline no past exercise habits and three or more barriers to exercise. These findings concur with both health behaviour theory [31] and studies in healthy elderly $[10,32]$ and cardiac $[33,34]$ populations, in which past habits and barriers were strong predictors of future physical activity. Interventions that specifically target self-efficacy and barriers may be beneficial both during and following completion of rehabilitation.

In our longitudinal study, rehabilitation setting did not differ significantly between activity trajectory classes. In the companion randomised trial comparing home and hospital outpatient rehabilitation, baseline to $1 \mathrm{yr}$ changes in dyspnoea, exercise tolerance and health status were similar in both experimental groups [15]. These results suggest that the initial rehabilitation setting does not influence longer-term activity patterns (longitudinal study) or clinical outcomes (ransomised clinical trial). In a small randomised trial $(n=45)$ [35], it was reported that improvements in exercise capacity were better maintained at 18 months in the home group than hospital-based programme. More work is needed, however, to better understand the specific components of home or hospital exercise training and how they may optimise or hinder longer-term maintenance of physical activity.

Exacerbations and endurance activity were measured concurrently during the 4-12-month period, and therefore the temporal relationship between these variables is unclear. Results from class comparisons suggest that individuals who are more prone to exacerbations also have difficulty in maintaining endurance activity (Chi-squared $\mathrm{p}<0.05)$. This finding is consistent with a 1yr follow-up study [6], in which the most commonly self-reported reason for not exercising, following completion of rehabilitation, was a chest infection. The importance of exercise barriers observed in our study points to an area often overlooked in pulmonary rehabilitation and that requires further investigation. Our results suggest that barriers are particularly relevant for individuals with characteristics consistent with the high/decline group. Health professionals should guide patients in identifying barriers and in developing strategies to minimise the potential effect of these barriers on physical activity.

One limitation to our study was the use of a self-reported measure to assess physical activity; however, this limitation was mitigated by several factors. Although self-reported measures can overestimate physical activity under certain conditions [36], this is not the case when subjects are familiar with the activity protocol and when the timing and type of activity are self-chosen [37], as was the situation in our study. Also, in longer-term studies, assessment tools such as patient-completed diaries or activity monitors worn on the subject's body serve as reminders and may cause a change in behaviour. This phenomenon is called reactivity, a change in behaviour resulting from study procedures [38]. The interviewer-administered log used in the current study was nonintrusive, an important benefit given the observational design and long duration of follow-up.

Strengths of our study included the large sample size, longitudinal design necessary to observe behavioural patterns that change over time, and trajectory modelling to capture this change and identify subgroups within a heterogeneous study sample.

In conclusion, weekly time spent in endurance activity showed an overall decline following participation in a 3-month pulmonary rehabilitation programme. Three distinct patterns were identified through trajectory modelling, two of which indicated difficulty in maintaining endurance activity. By identifying individuals with barriers to exercise and implementing appropriate interventions during and after the rehabilitation programme, it may be possible to promote better long-term involvement in physical activity. Future research should evaluate the effect of behavioural interventions aimed at minimising these barriers.

\section{STATEMENT OF INTEREST}

None declared.

\section{ACKNOWLEDGEMENT}

Completion of this study was possible because of the dedication of the investigators and study personnel at each participating centre, as follows. Hôpital Laval, Ch Sainte-Foy, Quebec, Canada: S. Bernard, D. Légaré, M-J. Breton, B. Jean, H. Villeneuve, M. Paquin, C. Gignac, M. Couture and E. Bernard; Montreal Chest Institute, Montreal, Quebec: P. Mancino, A. Joubert, I. Drouin, A. Hatzoglou and H. M'Kaouar; Halifax Infirmary Hospital Site Queen Elizabeth II Health Sciences Centre, Halifax, Nova Scotia: P. Hernandez, T. Seaman, E. McAndrew, A. Dale and C. MacDonald; Centre Hospitalier Universitaire Associé de Québec, Centre de Recherche de l'Institut Universitaire de Cardiologie et de Pneumologie de Québec, Quebec: M. Rouleau, G. Dubé and L. Pagé; Mont-Sinai Hospital, Montreal, Quebec: M. Baltzan, J-L. Sully, B. Major, M. Mierzwinski, M. Stathatos and M. Houde; Hôpital SacréCoeur, Montreal: M. Julien, L. Pineau, C. St-Arnaud, S. Valois and A. Gagnon; Jewish Rehabilitation Hospital, Laval, Quebec: B. Paradis, A. Berthiaume, L. Boutin, L. Cossette, M. Boggia and L. Campo; Hôpital Hôtel-Dieu de Lévis, Lévis, Quebec: R. Lecours, J. Morin and J. Bédard; UBC iCapture Centre for Cardiopulmonary Research, St Paul's Hospital, Vancouver, British Columbia: R. Levy, P. Camp, J. Burns, R. Johnston and F. Topp; Centre Hospitalier Baie-des-Chaleurs, Maria, Quebec: R. Audet, N. Loiselle, L. Boudreau, D. Cyr, R. Robichaud, V. Delarosbile, A. Allard and C. Leblanc. The authors also thank É. Rousseau, Y. Fortier and D. Janvier from the Laboratoire de Télématique Biomédicale du Réseau en Santé Respiratoire du FRSQ CHUS, Faculté de Médecine et des Sciences de la Santé 3001, Sherbrooke, Canada.

\section{REFERENCES}

1 Lacasse Y, Goldstein R, Lasserson TJ, et al. Pulmonary rehabilitation for chronic obstructive pulmonary disease. Cochrane Database Syst Rev 2006; 4: CD003793.

2 Goldstein RS, ZuWallack RL. Long-term compliance after chronic obstructive pulmonary disease rehabilitation. In: Donner $\mathrm{CF}$, Ambrosino N, Goldstein RS, eds. Pulmonary Rehabilitation. London, Hodder Arnold, 2005; pp. 369-376.

3 Griffiths TL, Burr ML, Campbell IA, et al. Results at 1 year of outpatient multidisciplinary pulmonary rehabilitation: a randomised controlled trial. Lancet 2000; 355: 362-368.

4 Ries AL, Kaplan RM, Myers R, et al. Maintenance after pulmonary rehabilitation in chronic lung disease: a randomized trial. Am J Respir Crit Care Med 2003; 167: 880-888. 
5 Troosters T, Gosselink R, Decramer M. Short and long-term effects of outpatient rehabilitation in patients with chronic obstructive pulmonary disease: a randomized trial. Am J Med 2000; 109: 207-212.

6 Brooks D, Krip B, Mangovski-Alzamora S, et al. The effect of postrehabilitation programmes among individuals with chronic obstructive pulmonary disease. Eur Respir J 2002; 20: 20-29.

7 Heppner PS, Morgan C, Kaplan R, et al. Regular walking and longterm maintenance of outcomes after pulmonary rehabilitation. J Cardiopulm Rehabil 2006; 26: 44-53.

8 Berry MJ, Rejeski WJ, Adair NE, et al. A randomized, controlled trial comparing long-term and short-term exercise in patients with chronic obstructive pulmonary disease. J Cardiopulm Rehabil 2004; 23: 60-68.

9 Emery CE, Shermer RL, Hauck ER, et al. Cognitive and psychological outcomes of exercise in a 1-year follow-up study of patients with chronic obstructive pulmonary disease. Health Psychol 2003; 22: 598-604.

10 McAuley E, Lox C, Duncan TE. Long-term maintenance of exercise, self-efficacy, and physiological change in older adults. J Gerontol 1993; 48: 218-224.

11 Rejeski WJ, Brawley LR, Ettinger W, et al. Compliance to exercise therapy in older participants with knee osteoarthritis: Implications for treating disability. Med Sci Sports Exerc 1997; 29: 977-985.

12 Kaplan RM, Atkins CJ, Reinsch S. Specific efficacy expectations mediate exercise compliance in patients with COPD. Health Psychol 1984; 3: 223-242.

13 Hellman EA. Use of the stages of change in exercise adherence model among older adults with a cardiac diagnosis. J Cardiopulm Rehabil 1997; 17: 145-155.

14 Nelson ME, Rejeski WJ, Blair SN, et al. Physical activity and public health in older adults: Recommendation from the American College of Sports Medicine and the American Heart Association. Circulation 2007; 116: 1094-1105.

15 Maltais F, Bourbeau J, Shapiro S, et al. Effects of home-based pulmonary rehabilitation in patients with chronic obstructive pulmonary disease: a randomized clinical trial. Ann Intern Med 2008; 149: 869-878.

16 Knudson RJ, Slatin RC, Lebowitz MD, et al. The maximal expiratory flow-volume curve. Normal standards, variability, and effects of age. Am Rev Respir Dis 1976; 113: 587-600.

17 Brooks SM. Surveillance for respiratory hazards. ATS News 1982; 8: 12-16.

18 American Thoracic Society. ATS statement: Guidelines for the sixminute walk test. Am J Respir Crit Care Med 2002; 166: 111-117.

19 Jones PW, Quirk FH, Baveystock CM, et al. A self-complete measure of health status for chronic airflow limitation. The St. George's Respiratory Questionnaire. Am Rev Respir Dis 1992; 145: 1321-1327.

20 Brink TL, Yesavage JA, Lum O. Screening tests for geriatric depression. Clin Gerontol 1982; 1: 37-43.

21 McAuley E, Jerome GJ, Marquez DX, et al. Exercise self-efficacy in older adults: social, affective, and behavioural influences. Ann Behav Med 2003; 25: 1-7.
22 Sechrist KR, Walker SN, Pender NJ. Development and psychometric evaluation of the exercise benefits/barriers scale. Res Nurs Health 1987; 10: 357-365.

23 Wedzicha JA, Seemungal TA. COPD exacerbations: defining their cause and prevention. Lancet 2007; 370: 786-796.

24 Pereira MA, Fitzgerald SJ, Joswiak ML, et al. Seven-day activity recall. Med Sci Sports Exerc 1997; 29: 89-103.

25 Johnson MF, Nichols JF, Sallis JF, et al. Interrelationships between physical activity and other health behaviours among university females and men. Prevent Med 1998; 27: 536-544.

26 Muthén B. Latent variable analysis: growth mixture modelling and related techniques for longitudinal data. In: Kaplan D, ed. Handbook of Quantitative Methodology for the Social Sciences. Newbury Park, Sage Publications, 2004; pp. 345-368.

27 Mplus User's Guide. 4th Edn. Los Angeles, Muthén \& Muthén, 2006.

28 Pauwels R, Buist AS, Calverley PM. Global strategy for the diagnosis, management, and prevention of chronic obstructive pulmonary disease. NHLBI/WHO Global Initiative for Chronic Obstructive Lung Disease (GOLD) workshop report. Am J Respir Crit Care Med 2001; 163: 1256-1276.

29 Pitta F, Troosters T, Spruit MA, et al. Characteristics of physical activities in daily life in chronic obstructive pulmonary disease. Am J Respir Crit Care Med 2005; 171: 972-977.

30 Belza B, Steele BG, Hunziker J, et al. Correlates of physical activity in chronic obstructive pulmonary disease. Nurs Res 2001; 50: 195202.

31 Bandura A. Social cognitive theory: an agentic perspective. Ann Rev Psychol 2001; 52: 1-26.

32 Rhodes RE, Martin AD, Taunton JE. Temporal relationships of self-efficacy and social support as predictors of adherence in a 6month strength-training program for older females. Percept Mot Skills 2001; 93: 693-703.

33 Moore SM, Dolansky MA, Ruland CM, et al. Predictors of females' exercise maintenance after cardiac rehabilitation. I Cardiopulm Rehabil 2003; 23: 40-49.

34 Johnson NA, Heller RF. Prediction of patient nonadherence with home-based exercise for cardiac rehabilitation: the role of perceived barriers and perceived benefits. Prev Med 1998; 27: 56-64.

35 Strijbos JH, Postma DS, van Altena R, et al. A comparison between an outpatient hospital-based pulmonary rehabilitation program and a home-care pulmonary rehabilitation program in patients with COPD. A follow-up of 18 months. Chest 1996; 109: 366-372.

36 Pitta F, Troosters T, Spruit MA, et al. Activity monitoring for assessment of physical activities in daily life in patients with chronic obstructive pulmonary disease. Arch Phys Med Rehabil 2005; 86: 1979-1985.

37 Warms C. Physical activity measurement in persons with chronic and disabling conditions: methods, strategies, and issues. Fam Community Health 2006; 29: 78S-88S.

38 Nelson RO, Hayes SC. Theoretical explanations for reactivity in self-monitoring. Behav Mod 1981; 5: 3-14. 